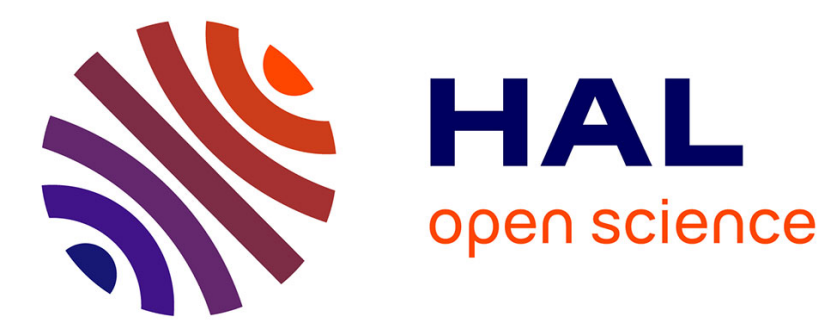

\title{
Should specialized oncogeriatric surgeons operate older unfit cancer patients?
}

\author{
B.L. van Leeuwen, S. Rostoft Kristjansson, R.A. Audisio
}

\section{To cite this version:}

B.L. van Leeuwen, S. Rostoft Kristjansson, R.A. Audisio. Should specialized oncogeriatric surgeons operate older unfit cancer patients?. EJSO - European Journal of Surgical Oncology, 2010, 36, 10.1016/j.ejso.2010.06.018 . hal-00612395

\section{HAL Id: hal-00612395 \\ https://hal.science/hal-00612395}

Submitted on 29 Jul 2011

HAL is a multi-disciplinary open access archive for the deposit and dissemination of scientific research documents, whether they are published or not. The documents may come from teaching and research institutions in France or abroad, or from public or private research centers.
L'archive ouverte pluridisciplinaire HAL, est destinée au dépôt et à la diffusion de documents scientifiques de niveau recherche, publiés ou non, émanant des établissements d'enseignement et de recherche français ou étrangers, des laboratoires publics ou privés. 


\section{Accepted Manuscript}

Title: Should specialized oncogeriatric surgeons operate older unfit cancer patients?

Authors: B.L. van Leeuwen, S. Rostoft Kristjansson, R.A. Audisio

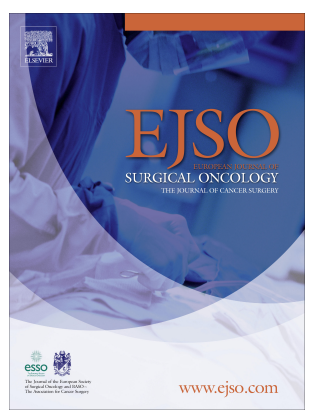

PII: S0748-7983(10)00194-0

DOI: $\quad$ 10.1016/j.ejso.2010.06.018

Reference: $\quad$ YEJSO 3006

To appear in: European Journal of Surgical Oncology

Received Date: 10 May 2010

Accepted Date: 7 June 2010

Please cite this article as: van Leeuwen BL, Rostoft Kristjansson S, Audisio RA. Should specialized oncogeriatric surgeons operate older unfit cancer patients?, European Journal of Surgical Oncology (2010), doi: 10.1016/j.ejso.2010.06.018

This is a PDF file of an unedited manuscript that has been accepted for publication. As a service to our customers we are providing this early version of the manuscript. The manuscript will undergo copyediting, typesetting, and review of the resulting proof before it is published in its final form. Please note that during the production process errors may be discovered which could affect the content, and all legal disclaimers that apply to the journal pertain. 


\section{Should specialized oncogeriatric surgeons operate older unfit cancer patients?}

B.L. van Leeuwen ${ }^{1}$, S. Rostoft Kristjansson ${ }^{2}$, R.A. Audisio ${ }^{3}$

${ }^{1}$ Department of surgery, University Medical Center Groningen, The Netherlands, ${ }^{2}$ Department of Geriatric Medicine, University of Oslo, Oslo University Hospital, Norway, ${ }^{3}$ Department of surgery, University of Liverpool, Whiston Hospital, Prescot, United Kingdom 


\section{Introduction}

Increasing age is one of the strongest risk factors for cancer development ${ }^{1}$. Life expectancy is continuingly increasing, and in many countries it advances by several hours per day ${ }^{2}$. Thus, the number of older adults with cancer is likely to increase over the coming years. Surgical treatment has a pivotal role in offering long-term survival for cancer patients with solid tumors. Furthermore, when cure cannot be achieved, surgery can palliate symptoms and improve quality of life. Cancer registry data from the Netherlands and Norway have shown that surgical management of lung, prostate, and rectal cancer steadily decline with increasing age ${ }^{3,4}$. For lung cancer, this trend prevails even when correcting for co-morbidity 5 . Conversely, the resection rate for colon cancer remains high even in advanced age.

Under elective conditions, there is a marked variability in the prevalence of postoperative complications according to cancer site and type of operation. In one study of cancer surgery in patients aged 70 years and older, 30-50\% developed post-operative complications, and half of them were major, potentially lifethreatening ones ${ }^{6}$. The emergency setting is associated with an excessively high mortality and morbidity rate, even more pronounced in elderly patients ${ }^{7-9}$.

For surgeons deciding upon treatment in older adults with a solid tumor, a number of challenges have to be faced. Firstly, there is little evidence from the medical literature regarding this group of patients because they are often excluded from clinical trials due to advanced age and/or severe co-morbidity ${ }^{10}$. Secondly, the elderly population is characterized by a marked variability in the rate of aging, and chronological age does not accurately reflect remaining life expectancy and treatment tolerance. Patients of the same age may be frail, with severe co-morbidity and functional impairment, or fit, with no co-morbidities and a high physical activity level. Thirdly, the training of oncologists and surgeons is mainly focused on choosing the best therapy for physically fit younger patients. Geriatricians, who are experienced in dealing with elderly patients, have limited knowledge about oncology and surgery.

Over the recent years, orthogeriatric units for hip fracture patients and acute care of the elderly units have been proven beneficial for frail elderly ${ }^{11-13}$. These units have been organized in a geriatric-based setting, demonstrating lower in-hospital mortality rates. Such units are seeking to provide all surgical, medical, and rehabilitation needs of the complex frail elderly patients in one single unit in the hospital. It is possible that a similar approach would benefit frail cancer patients.

\section{DECISION-MAKING IN ELDERLY PATIENTS}

Almost all age-related changes lead to reduced function and physiological decline, and chronological age is an important predictor of morbidity. However, due to the variability in the rate of functional deterioration, an individualized 
assessment of elderly patients in order to establish their biological age is necessary. An important first step in the decision-making process is to determine remaining life expectancy, which will depend on chronological age, co-morbidity, and functional status. Knowing the distribution of remaining life expectancy at different ages is useful. It has been calculated from US statistics that among women who have reached 80 years, $25 \%$ will live more than 13 years, approximately $50 \%$ will live for at least nine years (median), while $25 \%$ will live shorter than five years ${ }^{14}$. The most important determinants are functional status (does the patient need daily assistance?) and number and severity of comorbidities.

The next step would be to evaluate whether the cancer represents a threat to the patient's health or function within her remaining lifetime. The term competing risks describes how a number of diseases may compete to threaten the patient's life ${ }^{15}$. It must also be considered whether the cancer and complications from the cancer represents a threat to functional status and quality of life. The risk of having surgery must be weighted against the risk of not having surgery. It is well documented that both caregivers and health professionals under-estimate the older adult's willingness to undergo treatment ${ }^{16}$. Furthermore, older adults in general want to know about their diagnosis and prognosis. In a study published in $2001,88 \%$ of patients over the age of 65 wanted as much information as possible about their cancer disease ${ }^{17}$. However, among patients who required assistance in their activities of daily living, $28 \%$ did not want to know details about their cancer diagnosis.

In summary, the decision-making process requires that the surgeon has sufficient knowledge about remaining life expectancy of the patient, the anticipated natural progress of the cancer disease, and the risks of surgery for the individual patient. Furthermore, in order to tailor pre-operative counseling, the surgeon needs to know if the patient has cognitive dysfunction, and he or she should be sensitive to the patient's preferences regarding information about the disease and prognosis. 


\section{PRE-OPERATIVE ASSESSMENT OF ELDERLY CANCER PATIENTS}

The lack of evidence and the variability within the elderly population put the usefulness of established preoperative assessment tools, such as the American Society of Anesthesiologists Physical Status Classification System (ASA classification) into question. Recent evidence from cohorts of elderly colorectal cancer patients indicate that the majority of electively operated patients are classified as ASA II or ASA III, and that the ASA classification is not sufficiently sensitive to predict differences in operative risk between those two groups ${ }^{18,19}$. In geriatric medicine, elderly patients are systematically assessed across areas where they frequently present with problems: functional status, co-morbidity, nutritional status, emotional status, polypharmacy, cognitive function, and social support. This comprehensive geriatric assessment (CGA) allows for an estimate of the patient's remaining life expectancy, functional reserves, and treatment tolerance. Furthermore, CGA may uncover previously unknown medical problems, in addition to providing information with importance to adherence to treatment protocol and improving discharge planning. In the Preoperative Assessment of Cancer in the Elderly (PACE) study, elements from CGA were found to predict post-operative complications ${ }^{20}$. A recent study including a cohort of 178 elderly colorectal cancer patients with a median age of 80 years also found that CGA, but not increasing age, predicted surgical morbidity ${ }^{18}$.

The main drawback of CGA is that it is a time-consuming assessment. A number of shorter screening tools are being tested. The aim is to identify frail elderly patients who will benefit from a full CGA. Frailty describes an elderly patient who is at heightened vulnerability to adverse health status change because of a multisystem reduction in reserve capacity ${ }^{21}$. How to identify frailty, however, remains controversial. A frail patient is likely to have several issues that will be identified through CGA, such as cognitive dysfunction, malnutrition and functional limitations, issues that increase the surgical risk. In some cases, these risks may be addressed and decreased. As an example, pre-operative cognitive dysfunction increases the risk of post-operative delirium. It has been shown that a multicomponent intervention, including early mobilization, early interventions for volume depletion, and communication methods (eyeglasses and hearing aids) may prevent delirium ${ }^{22}$. 


\section{POST-OPERATIVE OUTCOMES}

When discussing elderly patients and outcomes after surgery the emphasis has usually been on short term outcomes and survival. ${ }^{23,24}$ This is not without reason; surviving surgery used to be an accomplishment in itself. However, in past decades anesthesiological techniques and peri-operative care have evolved to such an extent that early post-operative death is rare, even in the elderly population. Reports on outcomes after (major) surgical interventions in the elderly population have been positive, emphasising that in the fit elderly patient there is no limit to which surgical interventions can be performed, and outcomes are comparable to that in younger generations. ${ }^{25,26}$ Several major problems remain when interpreting these seemingly positive results. Firstly, there is the problem of patient selection. As discussed above there is no uniform definition of fit or frail, and even less uniform are the screening tools used to identify whether the patient is in one category or the other. Secondly, there certainly is more to life after surgery than survival. This holds true for every age category, but especially for the elderly as the remaining lifespan is less than in the younger age category. Preserving functional independence is key in maintaining quality of life in elderly, yet this outcome is rarely included in surgical publications. Lawrence and colleagues showed that of patients 60 years old or more, a substantial group experienced protracted disability at 6 months after major abdominal operations. Several components of physical and mental functioning did not return to preoperative levels. ${ }^{27}$ One interesting example of post-operative functional decline is post-operative cognitive dysfunction (POCD). This phenomenon may affect several aspects of cognitive functioning such as memory and concentration and occurs in patients of all ages. In contrast to what is generally believed, knowledge of the incidence and impact of POCD on quality of life is limited. ${ }^{28}$ There is neither a uniform definition of POCD in the literature, nor are there standardised diagnostic criteria. Although there are a few studies describing its incidence in an elderly surgical population, it has been studied more extensively in a younger population and in younger patients undergoing open heart surgery requiring cardio-pulmonary bypass. ${ }^{29,30}$ The causes of POCD are postulated to be multifactorial, but there is increasing evidence that the inflammatory response caused by the surgical procedure plays a role. ${ }^{31,32} \mathrm{~A}$ relation between POCD and the development of Alzheimer's disease has been suggested, but so far solid evidence is lacking. ${ }^{33}$ The older brain has a reduced potential for recovery compared to the younger brain, and it is therefore to be expected that postoperative cognitive decline in the elderly patient will have greater implications in terms of loss of independent functioning and quality of life. Part of our elderly population are only just able to function independently pre-operatively, any functional loss post-operatively will go hand in hand with increased consumption of care and increased costs.

A factor closely related with POCD is post-operative delirium. This acute cognitive complication is seldom reported in the surgical literature. 
There is a wide range of estimates of postoperative delirium, depending on type of surgical procedure. It is estimated to occur in $13-33 \%$ of patients undergoing elective abdominal aneurysm surgery ${ }^{34,35}$ and up to $60 \%$ of patients undergoing hip surgery ${ }^{36}$ Frail elderly are at increased risk of delirium with an incidence of up to $60 \% .{ }^{37}$ Although all elderly patients may be at some risk for the development of delirium, it is possible to identify patients at highest risk preoperatively and focus interventions on this group. ${ }^{38}$. This is especially interesting as postoperative delirium is predictive of the development of long term POCD.

Long term survival is seldom reported when discussing outcome after major surgical procedures in elderly patients. Rutten et al. showed that especially in the older patient categories ( $\geq 75$ years), the occurrence of complications after rectal surgery is associated with a higher post-operative mortality even at 6 months post-operatively. They go as far as to recommend non-surgical treatment for the frail elderly patient with rectal cancer. ${ }^{39}$ Similarly, Legner showed that postoperative complications after abdominopelvic surgery increase the rate of discharge to an institutional care facility for elderly patients. ${ }^{40}$ Both 30-day and 1 year mortality were increased in this patient category to $4.3 \%$ and $22.2 \%$, respectively, compared to patients discharged to their home. These potential risks of a surgical intervention require more investigation, and surgeons treating patients in the older age categories should be aware of them. 


\section{ALTERNATIVES TO SURGERY}

Technically, there is no difference between operating a solid tumor in an octogenarian or a 30-year old patient. If anything, the loss of firmness of tissue can make resections easier. The response to the intervention, however, may be very different, depending on the age and frailty category the patient belongs to.

In view of the above the old adagium "first do no harm" seems perfectly applicable to the elderly surgical population. Limiting the harm by limiting the surgical intervention, whilst maintaining oncological principles (ie still aiming at a radical resection of the tumor), seems a logical choice to make when faced with doubt about what treatment to choose. And this is exactly where the heart of the problem is. How do we decide what patient to operate on and what patient to decline a possibly life saving procedure? It has been reported that declining guideline breast surgery (including lymph node evaluation) to elderly women (even the octogenarians) substantially decreases breast cancer survival. ${ }^{41,42}$ As mentioned above regarding the treatment of rectal cancer in frail elderly patients, the mortality that can be related to the surgical procedure is sometimes too high to justify surgery. An interesting alternative to surgery in this respect is the treatment of patients with rectal tumors with chemoradiation only. ${ }^{43}$ Part of the patients treated in this way may not show any evidence of tumor recurrence, even after several years of follow-up.

In parallel to this approach, it has been shown that the wait and see approach for the surveillance of renal masses prevents overtreatment especially in the older and frail patient category. ${ }^{44}$ The surgical removal of renal cell carcinomas $<4 \mathrm{~cm}$ does not lead to a decrease in mortality, a fact that warrants consideration, especially in the frail elderly patient with decreased life expectancy.

Limiting the surgical resection to part of the affected organ may also be a good alternative in the treatment of some tumors. Transanal endoscopic microsurgery for T1 and T2 rectal tumors is a far less invasive procedure than rectal resection in elderly frail patients. ${ }^{45}$ For intraabdominal tumors in general, the laparoscopic approach seems to be associated with better immune and inflammatory responses and earlier post-operative recovery. Although the evidence is scarce, this minimally invasive surgical approach may especially benefit the elderly patient. ${ }^{46}$ Limited lung resections such as wedge resections for stage la lung cancer (tumors $<$ or $=2 \mathrm{~cm}$ ), instead of a formal lobectomy have recently been shown not to decrease cancer specific survival whilst causing less postoperative complications ${ }^{47}$ Again, this is an interesting alternative, especially for the frail elderly patient.

Self expanding metal stents appear to be a safe alternative to emergency surgery for obstructive colorectal cancer. ${ }^{48}$ They may be used as a bridge to surgery to avoid emergency surgery, as emergency surgery has a high mortality and morbidity. Stents may also be a suitable alternative in the palliative setting. 


\section{ROOM FOR IMPROVEMENT}

It is striking that the basic surgical curriculum offers little education in geriatric care. ${ }^{49}$ In our opinion there is room for improvement, not only concerning the training of doctors, but the training of nurses as well. Educating medical staff in the recognition of specific geriatric syndromes, such as delirium, and communication with hearing impaired elderly or patients with cognitive dysfunction is only the beginning of optimising peri-operative care. ${ }^{50}$ Furthermore, medical staff dealing with elderly patients need to be educated about managing co-morbidity and polypharmacy, and the importance of functional assessments for treatment planning. It is up to geriatricians and surgeons combined to change the omnipresent image that geriatric medicine is dull and stuffy. On the contrary, geriatric medicine is vibrant, complicated, and full of opportunities. We need to convince our hospital boards and governments that developing better education and care pathways for our frail elderly patients will require time and money. Many clinically relevant questions remain, leaving open a vast field of basic and general research.

Even with appealing alternatives, (major) surgical procedures will still be performed in unfit elderly patients in the future, and at an increasing rate. The question remains whether the decision making process and peri-operative care should be performed by specialized surgeons. Taking all of the above into account, from estimating frailty, to choosing the optimal treatment and optimising peri-operative care, it is evident that we need to improve the knowledge regarding taking care of elderly patients among surgeons. start training our surgeons how to take care of elderly patients. The elderly form such an essential part of the surgical population that it seems inappropriate to limit this training to specialized surgeons. However for the treatment of the frail subpopulation of elderly, educating dedicated surgeons may be justifiable.

The authors have no conflict of interest to report.

This paper was not funded through external sources. 


\section{REFERENCES}

1. DePinho RA: The age of cancer. Nature 408:248-254, 2000

2. Kirkwood TB: A systematic look at an old problem. Nature 451:644-7, 2008

3. Janssen-Heijnen MLG, Houterman S, Lemmens VEPP, et al: Prognostic impact of increasing age and co-morbidity in cancer patients: A population-based approach. Critical Reviews in Oncology/Hematology 55:231-240, 2005

4. Endreseth BH, Romundstad P, Myrvold HE, et al: Rectal cancer treatment of the elderly. Colorectal Disease 8:471-479, 2006

5. Peake MD, Thompson S, Lowe D, et al: Ageism in the management of lung cancer. Age and Ageing 32:171-177, 2003

6. Audisio RA, Pope D, Ramesh HS, et al: Shall we operate? Preoperative assessment in elderly cancer patients (PACE) can help. A SIOG surgical task force prospective study. Crit Rev Oncol Hematol 65:156-163, 2008

7. Turrentine FE, Wang H, Simpson VB, et al: Surgical risk factors, morbidity, and mortality in elderly patients. J Am Coll.Surg 203:865-877, 2006

8. Hamel MB, Henderson WG, Khuri SF, et al: Surgical outcomes for patients aged 80 and older: morbidity and mortality from major noncardiac surgery. J Am Geriatr.Soc 53:424-429, 2005

9. Leung JM, Dzankic S: Relative importance of preoperative health status versus intraoperative factors in predicting postoperative adverse outcomes in geriatric surgical patients. J Am.Geriatr.Soc. 49:1080-1085, 2001

10. Hutchins LF, Unger JM, Crowley JJ, et al: Underrepresentation of patients 65 years of age or older in cancer-treatment trials. N Engl J Med 341:20617, 1999

11. Adunsky A, Lusky A, Arad M, et al: A comparative study of rehabilitation outcomes of elderly hip fracture patients: the advantage of a comprehensive orthogeriatric approach. Journals of Gerontology Series A: Biological Sciences and Medical Sciences 58:542-547, 2003

12. Saltvedt I, Mo ES, Fayers P, et al: Reduced mortality in treating acutely sick, frail older patients in a geriatric evaluation and management unit. A prospective randomized trial. J Am Geriatr.Soc 50:792-798, 2002

13. Adunsky A, Arad M, Levi R, et al: Five-year experience with the 'Sheba' model of comprehensive orthogeriatric care for elderly hip fracture patients. Disabil Rehabil 27:1123-7, 2005

14. Walter LC, Covinsky KE: Cancer screening in elderly patients: a framework for individualized decision making. JAMA 285:2750-2756, 2001

15. Welch HG, Albertsen PC, Nease RF, et al: Estimating Treatment Benefits for the Elderly: The Effect of Competing Risks. Annals of Internal Medicine 124:577-584, 1996

16. Hamel MB, Lynn J, Teno JM, et al: Age-related differences in care preferences, treatment decisions, and clinical outcomes of seriously ill hospitalized adults: lessons from SUPPORT. J Am.Geriatr.Soc. 48:S176-S182, 2000

17. Ajaj A, Singh MP, Abdulla AJ: Should elderly patients be told they have cancer? Questionnaire survey of older people. BMJ 323:1160, 2001 
18. Kristjansson SR, Nesbakken, A., Jordhoy, M. S., Skovlund, E., Audisio, R. A., Johannessen, H. O., Bakka, A., Wyller, T.B.: Comprehensive geriatric assessment can predict complications in elderly patients after elective surgery for colorectal cancer: a prospective observational cohort study. Crit Rev Oncol Hematol In press , 2009

19. Sjo 0, Larsen S, Lunde 0, et al: Short term outcome after emergency and elective surgery for colon cancer. Colorectal Dis DOI: 10.1111/j.14631318.2008.01613.x, 2008

20. Shall we operate? Preoperative assessment in elderly cancer patients (PACE) can help A SIOG surgical task force prospective study. Crit Rev Oncol Hematol 65:156-163, 2008

21. Martin FC, Brighton P: Frailty: different tools for different purposes? Age and Ageing 37:129-131, 2008

22. Inouye SK, Bogardus ST, Charpentier PA, et al: A Multicomponent Intervention to Prevent Delirium in Hospitalized Older Patients. The New England Journal of Medicine 340:669-676, 1999

23. Al Refaie WB, Parsons HM, Henderson WG, Jensen EH, Tuttle TM, Vickers S M, Rothenberger DA, and Virnig BA. Major cancer surgery in the elderly: results from the American College of Surgeons National Surgical Quality Improvement Program. Ann.Surg. 251:311-318, 2010.

24. Massarweh NN, Legner VJ, Symons RG, McCormick WC, and Flum DR. Impact of advancing age on abdominal surgical outcomes. Arch.Surg. 144:11081114, 2009.

25. Gardner GJ. Ovarian cancer cytoreductive surgery in the elderly. Curr.Treat.Options.Oncol. 10:171-179, 2009.

26. Berry MF, Hanna J, Tong BC, Burfeind WR, Harpole DH, D'Amico TA and Onaitis MW. Risk factors for morbidity after lobectomy for lung cancer in elderly patients. Ann.Thorac.Surg. 88:1093-1099, 2009.

27 Lawrence VA, Hazuda HP, Cornell JE, Pederson T, Bradshaw PT, Mulrow CD, and Page CP. Functional independence after major abdominal surgery in the elderly. J.Am.Coll.Surg. 199:762-772, 2004.

28. Culley DJ, Xie Z, Crosby G. General anesthetic-induced neurotoxicity: an emerging problem for the young and old? Curr Opinion Anaesthesiol.20;408413,2007 .

29. Rasmussen LS, Postoperative cognitive dysfunction: Incidence and prevention. Best Pract Res Clin Anaesthesiol, 20;315-330,2006.

30. Stroobant, G. Van Nooten, D. DeBacquer, Y. Van Belleghem, and G.

Vingerhoets. Neuropsychological functioning 3-5 years after coronary artery bypass grafting: does the pump make a difference? Eur J Cardio-thor Surg, 396-401,2008.

31. van den Kommer TN, Dik MG, Comijs HC, Jonker C, Deeg DJH. Homocysteine and inflammation: Predictors of cognitive decline in older persons?. Neurobiol Aging. 2008, doi:10.1016/jneurobiolaging.2008.09.009 
32. Exel E, Craen AJM, Remarque EJ, Gussekloo et al. Interaction of atherosclerosis and inflammation in elderly subjects with poor cognitive function. Neurology; 61:1695-1701, 2003.

33. Hu Z, Ou Y, Duan K, Jiang X. Inflammation: A bridge between postoperative cognitive dysfunction and Alzheimer's disease. Med Hypotheses, doi:

10.1016/jmehy.2009.10.040

34. Ansaloni L, Catena F, Chattat R, Fortuna D, Franceschi C, Mascitti P, Melotti $\mathrm{RM}$. Risk factors and incidence of postoperative delirium in elderly patients after elective and emergency surgery. Br J Surg. 97:273-80, 2010.

35. Benoit AG, Campbell BI, Tanner JR, Staley JD, Wallbridge HR, Biehl DR, Bradley BD, Louridas G, Guzman RP, and Fromm RA. Risk factors and prevalence of perioperative cognitive dysfunction in abdominal aneurysm patients. J.Vasc.Surg. 42:884-890, 2005.

36. Marcantonio ER, Goldman L, Orav EJ, Cook EF, and Lee TH. The association of intraoperative factors with the development of postoperative delirium. Am.J.Med. 105:380-384, 1998.

37. Francis J., $\backslash$ Martin D, and Kapoor WN. A prospective study of delirium in hospitalized elderly. JAMA 263:1097-1101, 1990.

38. Beliveau MM and Multach M.. Perioperative care for the elderly patient. Med.Clin.North Am. 87:273-289, 2003.

39. Rutten HJ, den Dulk M, Lemmens VE, van de Velde CJ, and Marijnen CA. Controversies of total mesorectal excision for rectal cancer in elderly patients. Lancet Oncol. 9:494-501, 2008.

40. Legner VJ, Massarweh NN, Symons RG, McCormick WC, and Flum DR. The significance of discharge to skilled care after abdominopelvic surgery in older adults. Ann.Surg. 249:250-255, 2009.

41. Owusu C, Lash TL, and Silliman RA. Effect of undertreatment on the disparity in age-related breast cancer-specific survival among older women. Breast Cancer Res.Treat. 102:227-236, 2007.

42. Bouchardy C, Rapiti E, Fioretta G, Laissue P, Neyroud-Caspar I, Schäfer P, Kurtz J, Sappino AP, Vlastos G.J Undertreatment strongly decreases prognosis of breast cancer in elderly women. Clin Oncol. 21:3580-7, 2003.

43. Habr-Gama A and Perez RO. Non-operative management of rectal cancer after neoadjuvant chemoradiation. Br.J.Surg. 96:125-127, 2009.

44. Volpe A. The role of surveillance in the management of small renal masses. Scientific World Journal, 7: 860-868,2007.

45. Baatrup G, Breum B, Qvist N, Wille-Jorgensen P, Elbrond H, Moller P, and Hesselfeldt $P$. Transanal endoscopic microsurgery in 143 consecutive patients with rectal adenocarcinoma: results from a Danish multicenter study. Colorectal Dis. 11:270-275, 2009.

46. Tei M, Ikeda M, Haraguchi N, Takemasa I, Mizushima T, Ishii H, Yamamoto H, Sekimoto M, Doki Y, and Mori M. Postoperative complications in elderly patients with colorectal cancer: comparison of open and laparoscopic surgical procedures. Surg.Laparosc.Endosc.Percutan.Tech. $19: 488-492,2009$. 
47. Wisnivesky JP, Henschke CL, Swanson S, Yankelevitz DF, Zulueta J, Marcus S, Halm EA. Limited resection for the treatment of patients with stage IA lung cancer. Ann Surg, 251:550-554, 2010.

48. Sebastian S, Johnston S, Geoghegan T, Torreggiani W, Buckley M. Pooled analysis of the efficacy and safety of self expanding metal stenting in malignant colorectal obstruction. Am J Gastroenterol 99, 2051-2057, 2004.

49. Webb TP and Duthie E Jr. Geriatrics for surgeons: infusing life into an aging subject. J.Surg.Educ. 65:91-94, 2008.

50. Cicerchia M, Ceci M, Locatelli C, Gianni W, and Repetto L. Geriatric syndromes in peri-operative elderly cancer patients. Surg.Oncol., 2009 (in press). 